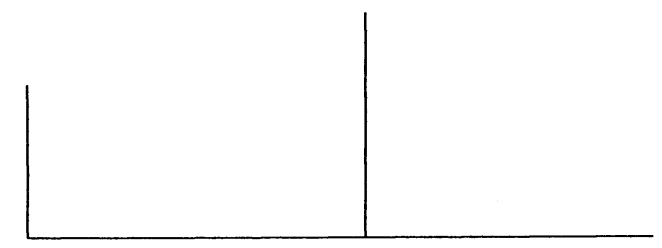

Rev. Latinoam. Psicopat. Fund., V, 1, 164-169

\title{
Doenças funcionais
}

\author{
Erney Plessmann de Camargo \\ Mônica Teixeira
}

Guimarães Rosa nos conta uma pequena história, aqui condensada e adaptada.

Reunidos alguns amigos, um deles usa, no meio da conversa, uma palavra inusitada. O Bom-Português, que estava na roda, interfere dizendo segura e enfaticamente: "Essa palavra não existe!".

Ao que o outro retruca: como não existe se acabei de pronunciá-la?!

Diálogo equivalente deve ocorrer diariamente em consultórios médicos do mundo inteiro.

Diz o médico: "O Sr. não tem nada."

Ao que o paciente poderia retrucar: "Como não tenho nada se sinto dor, se sinto isso e aquilo?!"

Por trás desse pequeno diálogo radica um eterno dilema médico, o confronto entre sinais (aquilo que é aparente, perceptível a um observador experiente) e sintomas (aquilo que é subjetivo, que o paciente sente, mas não é perceptível ao observador).

Há um século, e até menos, os professores de medicina davam muito valor aos sintomas e insistiam com seus alunos para prestarem atenção na história dos pacientes, pois eles estariam tentando lhes "contar" o diagnóstico.

Evidentemente, a maior parte da história dos pacientes erra sobre seus sintomas, isto é, suas dores e achaques, e a relação destes com seus 


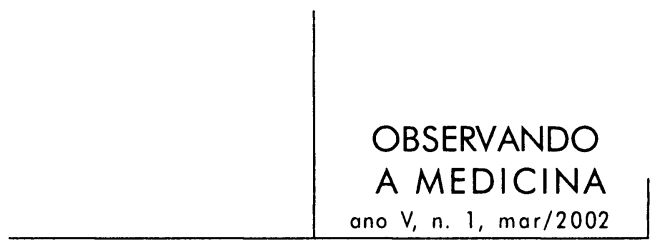

hábitos alimentares ou gerais, com a hora do dia ou da noite, enfim, sobre os sintomas de suas doenças. Para o diagnóstico, os médicos se baseavam nesses sintomas e em alguns poucos sinais como alterações na cor ou estrutura da pele e mucosas, cor da urina, febre, e em algumas informações resultantes da palpação de órgãos e ausculta dos pulmões e dos batimentos cardíacos. Em muitos e muitos casos, o diagnóstico só vinha na fase final da doença e talvez não fizesse muita diferença porque os recursos da medicina curativa eram igualmente limitados.

Porém, com o tempo, a medicina foi se "armando". Vieram os exames de sangue, de urina e de seus componentes. Vieram o raio-X, o eletrocardiograma, etc. Vieram as drogas e as inovações cirúrgicas. Desnecessário listar os recursos diagnósticos e terapêuticos da medicina contemporânea. Todos esses equipamentos e testes laboratoriais tinham, e têm, um objetivo em comum: detectar o quanto antes os sinais das doenças para poder tratá-las tão cedo quanto possível.

Infelizmente, ainda não foram inventados equipamentos para a detecção de sintomas. Sintomógrafos, sintomato-ressonância, rastreamento cintilosintomático e SPFC (Symptoms Probe and Failure Coherence) são aind a equipamentos e técnicas por conceber, inventar e aplicar. Dessa forma, no estado atual da arte, se o paciente disser que sente dor aqui ou acolá, o médico poderá "acreditar" ou não, quando o ideal seria poder constatar objetivamente a queixa. Essa situação é muito desconfortável para o médico, que se sente inseguro, com medo de comprometer a saúde do paciente seja acreditando, seja descrendo de queixas cuja veracidade ele não pode comprovar. Em virtude dessas e outras dificuldades operacionais, que incluem limitações de comunicação verbal e de vocabulário, os sintomas passaram a ocupar um plano secundário ao dos sinais na propedêutica médica.

Tornou-se cada vez mais difundida a prática médica de receber um paciente para uma primeira consulta curta e superficial e, em seguida, para uma consulta mais completa quando este retornar com uma bateria de resultados de exames, ou melhor, com uma lista confiável de sinais de doença. Aí o médico se sentirá mais seguro para ajudar o paciente. A detecção precoce de sinais é, evidentemente, melhor para ambos.

Mas o que acontece quando as doenças não têm sinais? O que acontece quando as queixas persistem ou aumentam e os sinais não surgem? Será o paciente um farsante? A farsa será consciente ou inconsciente? Terá o paciente um distúrbio psicológico com sintomas somáticos? Ou será que ele tem mesmo doenças reais que cursam sem sinais. Ou serão doenças que cursam com sinais, mas que a medicina ainda não aprendeu a detectar? 


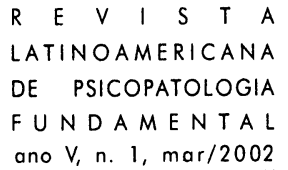

Essa é uma das muitas áreas cinzentas da medicina. Na realidade, entre 25 a $35 \%$ dos pacientes que consultam clínicas estatais da Europa ocidental o fazem por causa de "doenças" ricas em sintomas, mas pobres em sinais. Quase toda especialidade médica tem alguma doença desse tipo. Essas doenças são chamadas funcionais.

Vale a pena lembrar algumas delas, pelo menos as mais famosas.

Em Ginecologia são proeminentes a "tensão pré-menstrual" e a "dor pélvica crônica". A primeira é riquíssima na variedade de sintomas: ansiedade, nervosismo, raiva, falta de concentração, insônia, às vezes depressão e fadiga, palpitações, dor de cabeça, perda de apetite, náuseas, vômitos e mal-estar geral, enfim, uma constelação de sintomas sem sinais. Os sintomas aparecem antes da menstruação e podem durar de horas a dias, voltando a cada novo ciclo. Muitas vezes a doença é incapacitante durante seus episódios e pode acometer tanto mulheres jovens como adultas, sendo rara em multíparas. Só mais recentemente é que se têm encontrado alterações na produção e no metabolismo de estrógenos e progesterona. Porém, essas alterações não são diagnosticas per se.

A dor pélvica crônica, também chamada de dismenorréia primária, aparece na adolescéncia e tende a desaparecer com o amadurecimento da mulher e a gravidez. Os sintomas precedem as menstruações e duram de 1 a 2 dias, incluindo cólicas e dor pélvica com irradiação para a região sacral e parte posterior das coxas, dor de cabeça, náuseas e vômitos. Não são conhecidos sinais clínicos nem laboratoriais da doença.

Em reumatologia é bem conhecida a fibromialgia, ou síndrome da fibromialgia primária, que ocorre principalmente em mulheres jovens e que se manifesta por dores musculares agudas nos músculos do pescoço, dorso, região lombar e coxa. Ansiedade e depressão também estão associadas à síndrome, que muitos médicos consideram puramente psicológica. Não existem sinais de doença, apenas uma sensação dolorosa à palpação de regiões já doloridas.

Talvez as mais famosas dentre todas as doenças funcionais estejam no território da gastroenterologia. A síndrome do colo irritável prefere adultos jovens e seus sintomas incluem diarréia ou prisão de ventre, que podem se alternar ao longo do tempo, associadas à sensação dolorosa no baixo ventre. Os sintomas de desconforto e dor no ventre melhoram com a evacuação, mas em compensação deixam uma sensação de evacuação incompleta. Os sintomas podem ser desencadeados ou agravados por situações de estresse ou pela ingestão de determinados alimentos que, no entanto, variam de paciente para paciente. Sintomas de outras doenças funcionais (particularmente da fibromialgia e das cefaléias funcionais) costumam estar associados a esta síndrome. Os sintomas podem durar de meses a anos e desaparecem assim como vieram, sem causa aparente. 


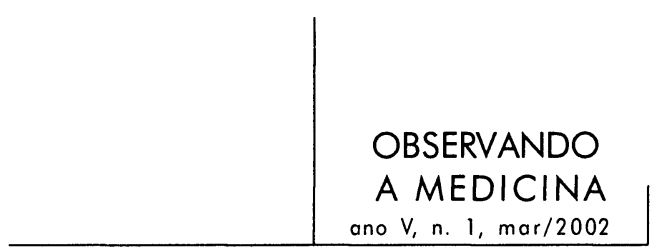

Outra síndrome gastroenterológica comum é a do bolo na garganta (Globus Syndrome, em inglês), em que o paciente se queixa de dificuldade de ingestão de alimentos, até mesmo os líquidos, por causa da sensação de entupimento, da existência de um obstáculo à ingestão causada pela presença de um corpo estranho em algum lugar ao longo do esôfago. Essa sensação de "não consigo engolir" está quase sempre associada a uma sensação de opressão no peito e muita ansiedade.

As cefaléias primárias compõem um conjunto de síndromes neurológicas muito difundidas e que acometem milhões e milhões de pessoas em todo o mundo. Entre elas se incluem a clássica enxaqueca, a cefaléia tensional e a cefaléia em salva. Esta última pode durar alguns minutos, enquanto as demais se estendem por horas e até dias. Mas todas se caracterizam por dor de cabeça intensa, náuseas e vômitos e distúrbios oculares. Os episódios dolorosos se repetem ao longo dos anos a intervalos variáveis. Os pacientes (e também os médicos) passam anos tentando associar o desencadeamento de um episódio a uma determinada circunstância, seja um alimento, seja um evento psicológico. Quase nunca conseguem. Vários medicamentos têm sido usados: analgésicos, alcalóides, betabloqueadores e, mais recentemente, antidepressivos. A resposta a estes medicamentos é extremamente variável e cada paciente parece se dar melhor com um determinado esquema terapêutico. Sofrem durante anos e de repente se curam.

Uma síndrome que ganhou reconhecimento médico há apenas alguns anos foi a síndrome da fadiga crônica. Cansaço permanente, desinteresse, inapetência, diminuição da libido, insônia, mau humor, fraqueza e sensação de doença são seus sintomas. Não existem sinais de doença, apenas a presunção de que a síndrome esteja associada a infecções virais passadas ou presentes.

Existem muitas outras doenças funcionais, entre elas a dor pré-cordial, não cardíaca, a dor da articulação têmporo-mandibular, a dor facial atípica e a síndrome da hiperventilação respiratória. Bastante conhecida é a síndrome da alergia química múltipla, em que o paciente sempre que exposto a agentes (vapores, cheiros de solventes ou perfumes, alimentos) que desencadearam episódios anteriores, respondem imediatamente com um novo episódio seja de cefaléia, de náuseas e vômitos, ou espirros em salva e exantemas, etc.

Todas essas doenças funcionais, embora não sejam çausa de morte, são causa de grande sofrimento e empobrecimento da qualidade de vida, às vezes agravada pela truculência médica. É difundida a história do paciente que, tendo sido advertido pelo médico de que ele "não tinha nada" e que tudo estava "em sua cabeça", suplica: "Então doutor, corta a cabeça porque eu não agüento mais".

Evidentemente essa caricatura não se aplica a todos os médicos e a toda a medicina. Pelo contrário, a maioria dos médicos se sentirão profissionalmente frustrados diante de uma doença funcional sem sinais. É fonte de grande 
preocupação para o médico não encontrar a causa de uma doença. Por exemplo, diante de uma síndrome de colo irritável, ele fará todos os exames para excluir desde uma simples polipose até um carcinoma de colo. Uma cefaléia pode esconder desde uma crise hipertensiva até um carcinoma cerebral. Portanto, o Bom-médico ficará extremamente preocupado quando não esclarecer adequadamente a etiologia da doença de um paciente.

O Bom-médico não declarará com arrogância: "O Sr. não tem nada". Isto, por várias razões. Primeiro, porque faz parte do orgulho profissional esclarecer as causas de sofrimento, as causas das doenças; segundo, porque é obrigação do médico aliviar esse sofrimento, a despeito de suas causas. Finalmente, porque o Bom-médico sofre tanto quanto o paciente diante do risco de não ter feito um diagnóstico correto e de estar pondo em risco sua vida.

Portanto, essas doenças funcionais são uma tragédia cotidiana para a medicina, para os pacientes e para o Bom-médico, e por essas razões têm sido intensamente investigadas.

Existe um sentimento bem difundido entre os clínicos de que, pelo menos em parte, as doenças funcionais são um produto da excessiva especialização médica. Pacientes procuram ou são encaminhados a especialistas em função de seus sintomas predominantes. Por sua vez, especialistas concentram-se nos sintomas referentes à sua especialidade, relegando a um segundo plano os sintomas comuns a outras doenças. Esses fatos fecham o ciclo vicioso de compartimentagem de doenças em função de especialidades.

Há algum tempo Wesseley, Nimnuan e Sharpe, de instituições de Londres e Edimburgo, vêm questionando a validade da classificação das doenças funcionais em entidades distintas subordinadas a diferentes especialidades. Em respeitável artigo no Lancet (n. 354, p. 936-9, 1999), esses psiquiatras, já há algum tempo, suscitaram a questão: "Síndromes funcionais: uma ou várias?". Em função de levantamentos bem conduzidos, chegaram à conclusão de que, se encaradas do ponto de vista do clínico geral, não do especialista, as doenças funcionais são, na realidade, uma só.

Seus principais argumentos:

1. Comparando as definições de 12 síndromes funcionais verificaram que os mesmos sintomas estavam presentes em muitas delas. Por exemplo, "flatulência" e "cefaléias" foram encontradas em 8 e "fadiga" e "dor abdominal" em 6;

2. sintomas típicos de uma dada síndrome, são também encontrados em outras. Por exemplo, pacientes com colo irritável freqüentemente referem dor têmporo-mandibular, dor pré-cordial não cardíaca, fadiga crônica, tensão prémenstrual, e fibromialgia;

3. pacientes com síndromes funcionais diferentes têm muitas características em comum. Por exemplo, a grande maioria é de mulheres (síndromes ginecoló- 


\section{OBSERVANDO}

A MEDICINA

ano $V$, n. $1, \operatorname{mar} / 2002$

gicas excluídas); existe uma associação significativa entre doenças funcionais e distúrbios psicológicos do tipo da ansiedade e depressão não severas; uma proporção maior do que a esperada de pacientes com doenças funcionais foi vítima de abuso sexual na infância, particularmente mulheres com dor pélvica crônica;

4. tratamento psicológico (senso lato) e uso de antidepressivos definitivamente auxiliam grande percentagem dos pacientes das várias síndromes funcionais, embora os estudos sejam pouco numerosos e não muito consistentes, até o momento.

Em função dessa análise, os pesquisadores concluem ser necessário substituir a atual classificação das doenças funcionais por uma que privilegie as grandes semelhanças entre elas, não suas pequenas diferenças. Analisam várias alternativas, entre elas a de reuni-las em subgrupos em função dos grandes sintomas, mas acabam chegando à conclusão de que o importante mesmo é considerá-las em conjunto e tirá-las do domínio das especialidades.

Quem cuidaria delas, então?

Embora os autores sejam psiquiatras e psicólogos, eles não recomendam que as doenças funcionais fiquem sob a tutela da psicologia-psiquiatria, dentro da categoria das doenças psicossomáticas ou síndromes somatiformes. Eles entendem que, apesar das limitações discutidas nesse artigo, o conhecimento sobre as doenças funcionais avançou muito sob a gestão das respectivas especialidades. Podem avançar ainda mais sob uma óptica de investigações multidisciplinares, em que especialistas, psiquiatras e generalistas interajam.

Wesseley, Nimnuan e Sharpe entendem que o melhor mesmo seria se os pacientes de doenças funcionais, em vez de serem encaminhados a especialistas, o fossem a clínicos gerais. Mas aí surge um grande problema. Clínicos gerais são cada vez mais raros. É verdade que, principalmente na Europa, existe um ressurgimento do Clínico geral ou Familiar. Contudo, entre nós, essa importante figura saiu um pouco da moda. Os próceres da medicina contemporânea são aqueles que sabem cada vez mais sobre menos coisas, não os que sabem o básico de todas as coisas. Ou seja, médicos famosos são especialistas, não generalistas. É pena, porque os pacientes de doenças funcionais continuarão perdidos entre consultórios de várias especialidades.

Uma alternativa seria - por meio de programas de educação médica continuada (ainda pouco difundidos no Brasil), ou da insistente inserção do tema "doenças funcionais multidisciplinares" em congressos de especialidades médicas - convencer o especialista a se comportar como generalista em pequena parte de seu tempo para atender, humana e abrangentemente, os pacientes de doenças funcionais.

Será isto possível? 